\title{
Infant Feeding and Cardiovascular Disease: A multi-staged analysis from global to country data
}

\author{
Azza Abul-Fadl, M.D.*, Ayoub Al-Jawaldeh**, PHD \\ Department of Nutrition Sciences, University of Vienna, UZA2 \\ Althantstrasse 14, 1090 Vienna, Austria \\ Corresponding Author: \\ Azza M.A.M Abul-Fadl
}

Professor of Pediatrics, Pediatric Department, Faculty of Medicine, Benha University, EGYPT

President of Mother Child Friendly Care Association [MCFC) www.mcfcare.org Address: 26B ElGezira AlWosta street, Zamalek, Cairo 11211, Egypt

\begin{abstract}
Background: Death from cardiovascular disease (CVD) is the leading cause of death globally and in particular in the Eastern Mediterranean region (EMR). The relationship between early feeding practices and CVD remains to be fully established.

Aim: To examine the relationship between early infant feeding practices, as risk factors of death from CVD, with a focus on high blood pressure (HBP), in the 22 countries of the EMR.

Methods: First: global and regional data were compiled for deaths from CVD, HBP, nutritional deficiencies. Second: data from the EMR countries were compiled for adult obesity, high cholesterol (HC) and blood sugar (HBS) and pollution. Countries from the EMR were divided into high and low risk by HBP and biochemical data. Third: deaths from wasting, stunting, non-exclusive and discontinued breastfeeding and nutritional deficiencies including anemia, vitamin A deficiency, low bone mineral density and Zinc deficiency, were compared in both groups. Fourth: a small scale in-depth study (SSIDS) was conducted for 32 breastfed and 28 non-breastfed mother-child pairs under-five years of age. HBP and high density lipoproteins (HDL) and low density lipoproteins (LDL) and highly sensitive C-reactive protein (HsCRP) were measured.

Findings: Nine out of the 22 EMR countries were identified as high risk for CVD with HBP, obesity, HC and HBS and pollution. Deaths from nutritional deficiencies and feeding practices were higher in this group. In the SSIDS, HsCPR was significantly lower in mothers and children who were breastfed and HDL significantly higher in children introduced foods after 6 months of age.

Conclusions: Optimal infant feeding practices contribute directly and indirectly to reducing deaths from CVD.
\end{abstract}

Key words: Global deaths, high blood pressure, obesity, lipids, cardiovascular disease, breastfeeding, pollution, nutritional status, weaning practices, cardiovascular biomarkers.

Disclosures: none

What's new in this research?

The research highlights the importance of infant and young child nutritional and feeding practices especially optimum breastfeeding practices and early weaning and their long term effects on increasing the burden of death from cardiovascular disease (CVD) as the leading cause of death globally. Research linking early exclusive breastfeeding and duration of breastfeeding to two years linked to CVD remain under researched. 
The Eastern Mediterranean region has the highest number of countries that suffer conflict, political instability and chronic emergencies which affect health care delivery and access to safe and adequate food supplies and development. A focus on improving childhood nutrition and feeding can impact long term outcomes in such populations.

\section{Background}

Globally approximately 17.7 million people die from cardiovascular disease (CVD). The majority (63 percent) of deaths occurred in the age bracket of 70 years and above. Just below 30 percent were aged 5069, and the remaining 7-8 percent aged 15-49 (CVD deaths in those aged 14 years and under are small). CVD death rates, expressed as the number of CVD deaths per year per 100,000 individuals, are on the rise (1).

High blood pressure (HBP) is the leading risk factor for CVD mortality amounting to 10.46 million, followed by smoking (6.3 million), high blood sugar (HBS) (5.61 million), high body mass index (BMI) (4.53 million), high cholesterol (4.39 million) and outdoor pollution (4.09 million) in $2016^{(1)}$. The global prevalence of HBP (defined as systolic and/or diastolic blood pressure $\geq 140 / 90 \mathrm{mmHg}$ ) in adults aged 18 years and over was around 22\% in 2014. It is estimated to have caused 9.4 million deaths and $7 \%$ of disease burden - as measured in disability-adjusted life years - in 2010. If left uncontrolled, hypertension causes stroke, myocardial infarction, cardiac failure, dementia, renal failure and blindness, causing human suffering and imposing severe financial and service burdens on health systems ${ }^{(2)}$.

Longer breastfeeding duration was found to be associated with a lower risk of cardiovascular disease (CVDs), especially hypertension ${ }^{(3,4,5,6)}$. A study of a cohort of 0.5 million Chinese women showed that breastfeeding for 24 months or more lowered the risk of coronary heart disease by $18 \%$ and risk of stroke by $17 \%$ and that increasing the duration of breastfeeding for 6 months or more reduced risk for coronary heart disease and stroke even further ${ }^{(7)}$.

Obesity is a known risk factor for HBP and CVD. Obesity is on the rise and is a significant public health problem in the EMR, where one half of the countries have the highest rates of obesity in the world. Breastfeeding is protective against later obesity ${ }^{(8)}$. Also exclusive breastfeeding (EBF) was found to be associated with lower adiposity and serum total cholesterol in children at 4 years of age. Likewise continued breastfeeding (CBF) for over 12 months was associated with lower adiposity. These data support the importance of EBF and CBF for later cardiometabolic health ${ }^{(8)}$.

However there is still ongoing controversy in the literature around breastfeeding duration and mortality risk from CVD ${ }^{(9)}$. Although CVD is the leading cause of death in developed countries, most of the studies on CVD and breastfeeding were conducted in developed countries, but few have been done in the developing countries. Moreover, in the EMR a considerable number of countries are either in conflict or recovering from conflict or affected indirectly by the effect of conflict by neighboring countries through influx of immigrants and their related problems. Such situations may increase the risk to death from CVD due to increased stress and its related effects.

Hence the aim of this work is to assess the risk to CVD, with a particular focus on hypertension, feeding practices and nutritional deficiencies as risk factors of CVD. Also to highlight the role of early infant feeding practices, mainly EBF, early discontinuation of breastfeeding and early introduction of weaning foods, on risk factors of CVD. This will be done through a multifaceted, multi-staged approach for analysis of risk from global to regional to small scale studies.

\section{Methods}

Study design: Global data for deaths from the World Health Organization (WHO) Global health estimates $(2015)^{(10)}$. While the data for the 22 countries of the Eastern Mediterranean region (EMR) were taken from "our world in data bases for causes of death" from the USA ${ }^{(1)}$. The data included annual deaths from cardiovascular disease (CVD) by risk factor for each of the 22 countries. The risk factors were grouped into six groups: I- high blood pressure (HBP), II- obesity using the cut off of body mass index (BMI) for adults; III- biochemical or metabolic disturbances including high cholesterol (HC) and high blood sugar (HBS); IVpollution including smoking, exposure to second hand smoking, exposure to household and indoor pollution; 
V- nutritional indices for children including low birth weight (LBW), wasting, stunting, iron deficiency anemia (IDA), vitamin A deficiency (VAD), low bone mineral bone density (LMBD) and zinc deficiency $(\mathrm{ZnD})$; and finally VI- Infant feeding practices including not exclusively breastfeeding (NEBF) and discontinued breastfeeding (DBF). The sum of the number of deaths for each group for the 22 countries in the region were summed and presented graphically and in mean and standard deviation score.

Source of data: Global data for the death rates by region were obtained from the World Bank and $\mathrm{WHO}^{(10)}$. Data from global sources were extracted from online sources (https://ourworldindata.org/causes-of-death). Data for total annual number of deaths from CVD by risk factor (for all age groups and for either sex) for 2016 World Bank data.

In the second stage of the study the countries were grouped into high risk of CVD death and low CVD risk of death according to HBP, HC, HBS and HBMI as follows:

I- $\quad$ Countries with High Risk of Cardiovascular Deaths (HRCD): These included 9 countries (Afghanistan, Egypt, Iraq, Iran, Morocco, Pakistan, Somalia, Sudan, Yemen).

II- Countries with Low Risk of Cardiovascular Deaths (LRCD): These included 13 countries (Bahrain, Djibouti, Jordan, Lebanon, Libya, Kuwait, Qatar, Oman, Palestine, Saudi Arabia, Syria, Tunisia, United Arab Emirates, UAE).

The mean number of deaths for deaths from nutritional status, micronutrient deficiency states and feeding practices were tabulated and compared between both groups as range (maximum and minimum total deaths, mean and standard deviation).

Data from a small scale in-depth study (SSIDS) were extracted from a thesis study from Benha University in Egypt, by permission, and reanalyzed ${ }^{(11)}$. The study was conducted in an urban setting in Cairo for 60 mothers and children were aged from 3 to 5 years. They were randomly grouped into 28 non breastfeed and 32 breastfed mother child pairs according to their past early feeding practices in the first two years of life. Their feeding practices were analyzed in relation to maternal systolic and diastolic blood pressure (SBP, DBP), maternal and child laboratory studies for blood levels of low and high density lipoproteins (LDL, HDL), LDL to HDL ratio (LDL/HDL) and plasma highly sensitive C-reactive protein (HsCRP), all of which were biomarkers of arteriosclerotic heart disease were compared in either group in relation to breastfeeding and timing of introduction of foods (at 4-6 months, at 6-9 months and after 9 months of age).

Statistical Analysis: The collected data were organized, tabulated and statistically analyzed first on excel sheets for initial analysis. The relevant data were further analyzed using a software statistical package (SPSS version 20, SPSS Inc; Chicago, Illinois). The qualitative data for the rates of breastfeeding and NCDs were presented as discrete data per country and presented in mean and standard deviation for the region. Student t-test (for parametric data) and Mann-Whitney U test (for non-parametric data) were used for comparison of 2 distinct groups. Correlative studies were done using Spearmann's correlation coefficient. The level of significance cut off used was $\mathrm{P}<0.05$.

\section{Results}

Figure (1) presents the most recent estimates of deaths from CVD, hypertension and malnutrition in 2015 (WHO, 2015). Globally the total deaths from CVD was 17,630, 938 representing 1,295,736 (7\%) from EMR; 4,23,898 (24\%) from the European region (EUR); 1,170,627 (7\%) from the African region (AFR), $3,838,792$ (22\%) from the South East Asian region (SEAR), 5,243,945 (30\%) from the West Pacific region (WPR) and 1,848,940 (11\%) from the America region (AMR). While WPR had the highest death rates from CVD, EMR and AFR had the lowest rates. 


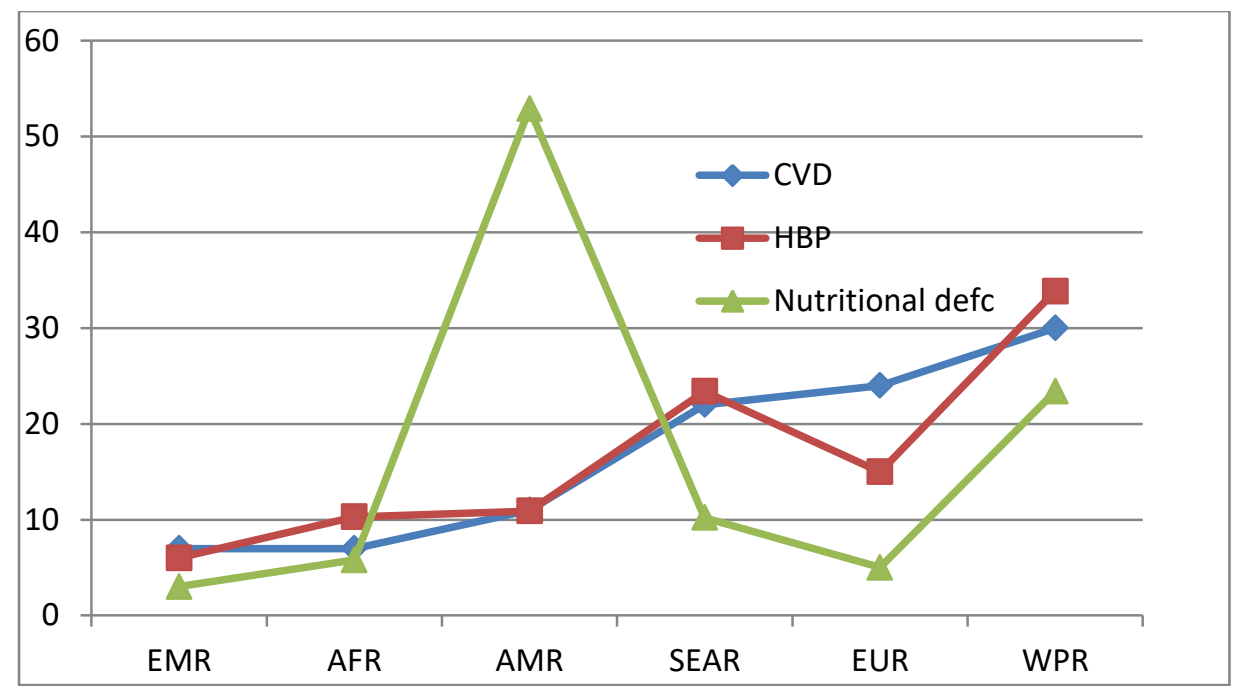

EMR: Eastern Mediterranean region, AFR: African region, SEAR: South East Asia region, EUR: European region, WPR: West Pacific region. Figure (1) Global percent distribution of deaths from cardiovascular diseases (CVD), hypertensive disease (HBP) and nutritional deficiencies by World Health Organization regions.

The total death rates from hypertensive disease were 938,128 with highest death from SEAR (317,617; $33.8 \%)$ and WPR $(219,386 ; 23.4 \%)$ versus the lowest from the EMR $(58,932 ; 6 \%)$ and AFR $(96,704$; $10.3 \%)$. Also, the total deaths from nutritional deficiencies were 438,388 with highest numbers coming from AMR $(231,912 ; 52.9 \%)$ and WPR $(102,777 ; 23.4 \%)$ and lowest from EMR $(601 ; 3.0 \%)$, Europe $(19,622$; $5.0 \%)$ and AFR $(25,620 ; 5.8 \%)$.

Figure (2) shows that the top seven countries with highest burden of deaths from hypertension, as a risk factor of deaths from CVD in the EMR are Pakistan (32.64\%), Egypt (17.05\%) and Iran (10.17\%), followed by Iraq, Morocco, Afghanistan and Sudan $(6.7 \%, 6.6 \%, 6.4 \%$ and 5.5\% respectively). Also burden of deaths from obesity, as a contributing cause of death from CVD are similarly high in these same countries.

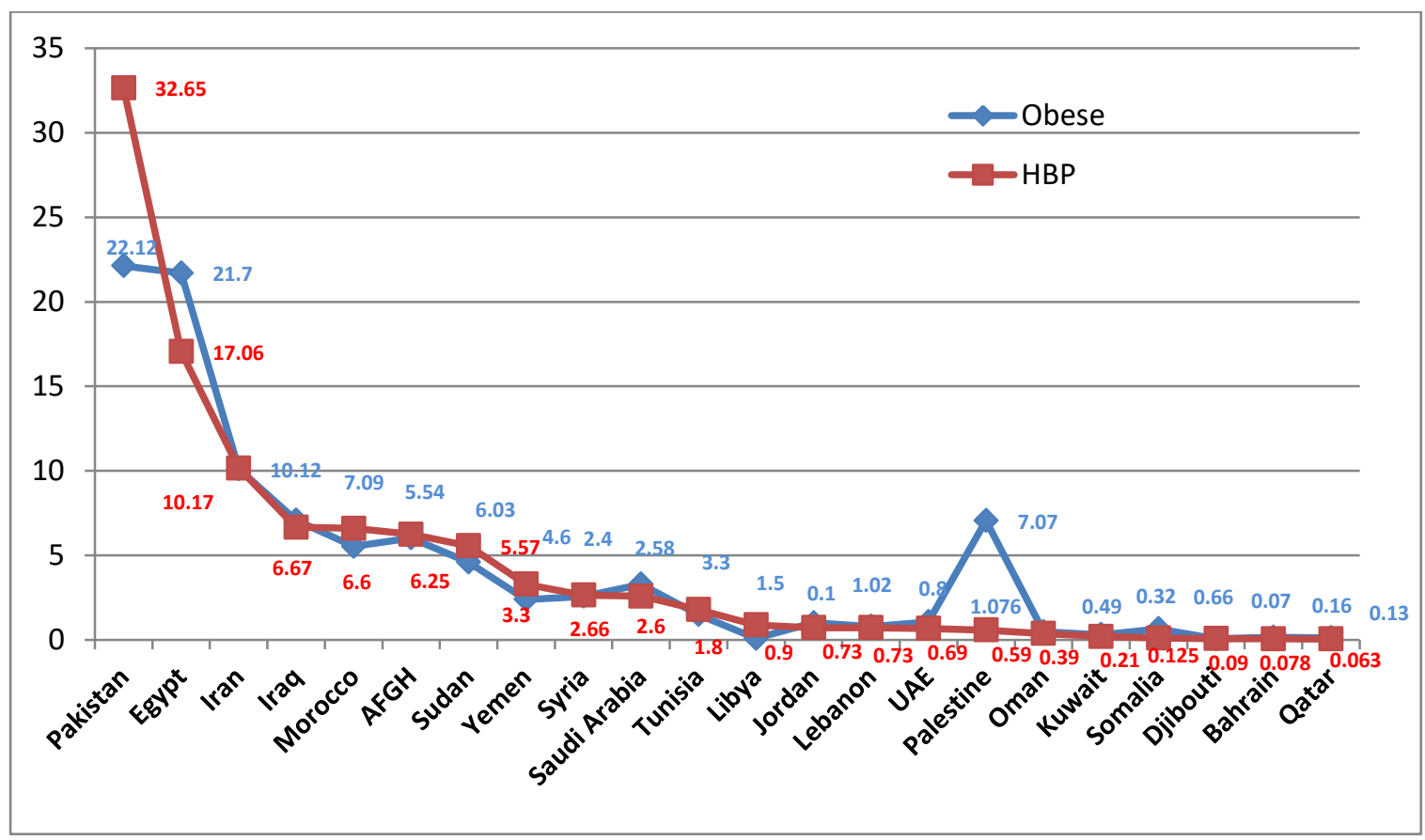

Figure (2) Distribution of high blood pressure and obesity (high BMI) as risk factors for death from cardiovascular disease, in each country as a percent of the total number of deaths from CVD in the Eastern Mediterranean Region.

Figure (3) shows the distribution of biochemical indices (HBS and HC) and pollution (outdoor and household pollution, smoking and second hand smoke), as risk factors for death from cardiovascular disease, in each country as a percent of the total number of deaths from CVD in the EMR. Pakistan, Egypt and Iran, 
alone, contribute to the highest proportion of risk from disturbances in biochemical indices (HBS and HC blood levels) (29.8\%, $18.1 \%$ and $11.2 \%$ respectively), representing two thirds of the burden of risk for CVD in the region as shown in figure 2. Deaths from CVD for the 22 countries attributable to HBS for the region was 259,936 , HC was 356,559 and from exposure to outdoor pollution was 350,852 and from indoor pollution was 76,277. Smoking and second hand smoking was 350,852 and 76,277 respectively.

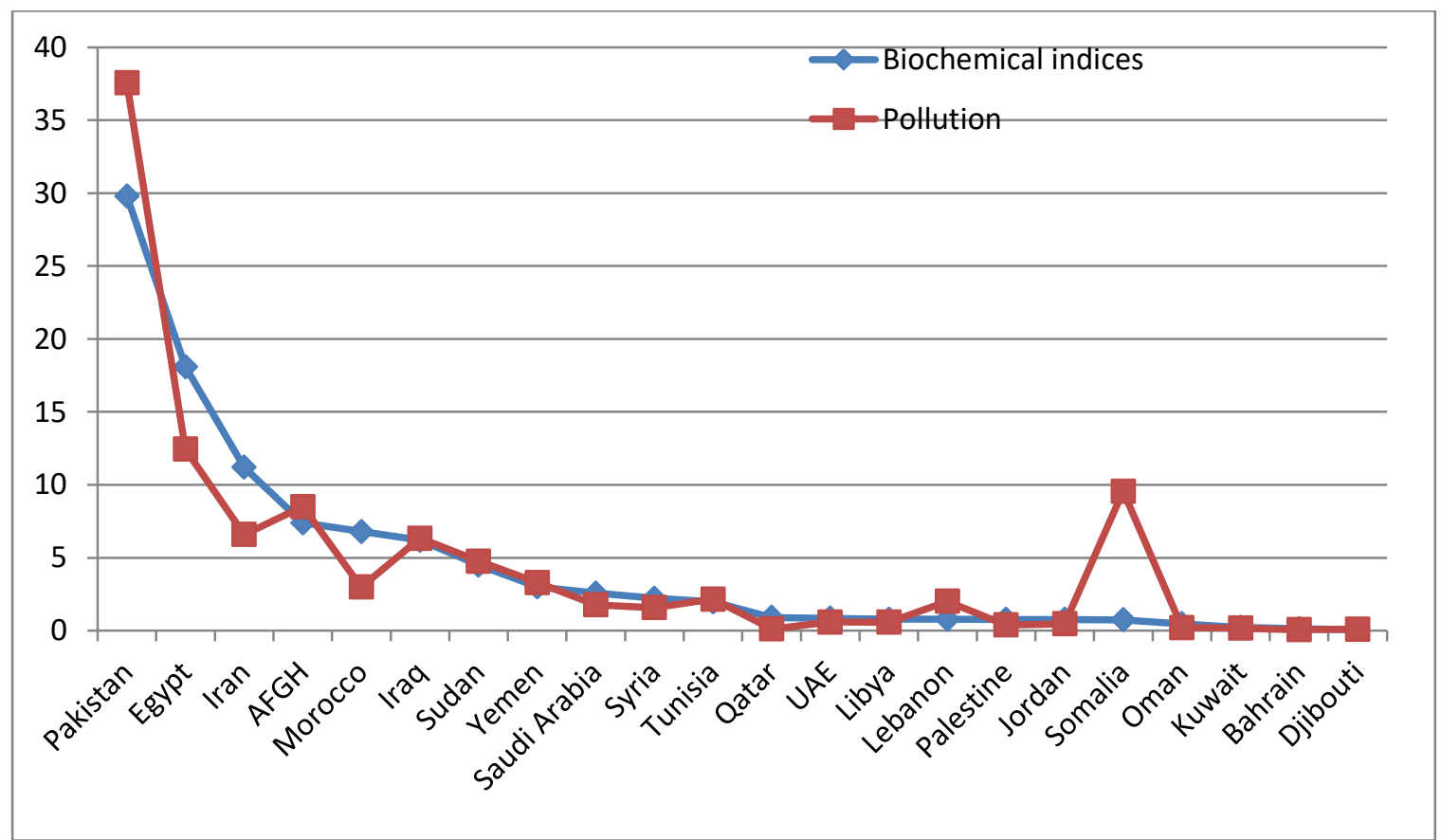

Figure (3) Distribution of biochemical indices (high blood sugar and high cholesterol) and pollution (outdoor, household, smoking and second hand smoke), as risk factors for death from cardiovascular disease (CVD), in each country as a percent of the total number of deaths from CVD in the Eastern Mediterranean Region.

Table (1) and Figure (4) present a comparison between the nine countries with high burden of deaths from the three major contributors of death from CVD with the 13 other countries with lower risk in range, mean and standard deviation. The number of deaths from LBW, wasting stunting, micronutrient deficiencies (IDA, VAD, LBMD, ZnD) and infant feeding practices (NEBF and NCBF) were significantly higher in the high risk countries (HRC) compared to the low risk countries (LRC). Statistical analysis showed significant differences for $\mathrm{BP}(\mathrm{t}=2.9332 \mathrm{p}=0.019)$, wasting $(\mathrm{t}=2.34, \mathrm{p}=0.047)$, stunting $(\mathrm{t}=2.29, \mathrm{p}=0.51)$, LBW ( $\mathrm{t}=2.65$, $\mathrm{p}=0.03)$, NEBF $(\mathrm{t}=2.4, \mathrm{p}=0.43), \operatorname{LBMD}(\mathrm{t}=2.75, \mathrm{p}=0.025),(\mathrm{t}=2.16, \mathrm{p}=0.063)$ and $\mathrm{ZnD}(\mathrm{t}=2.19, \mathrm{p}=0.06)$. There was no statistically significant difference for IDA $(\mathrm{t}=1.78, \mathrm{p}=0.112)$ and $\operatorname{NCBF}(\mathrm{t}=1.8, \mathrm{p}=0.108)$. 


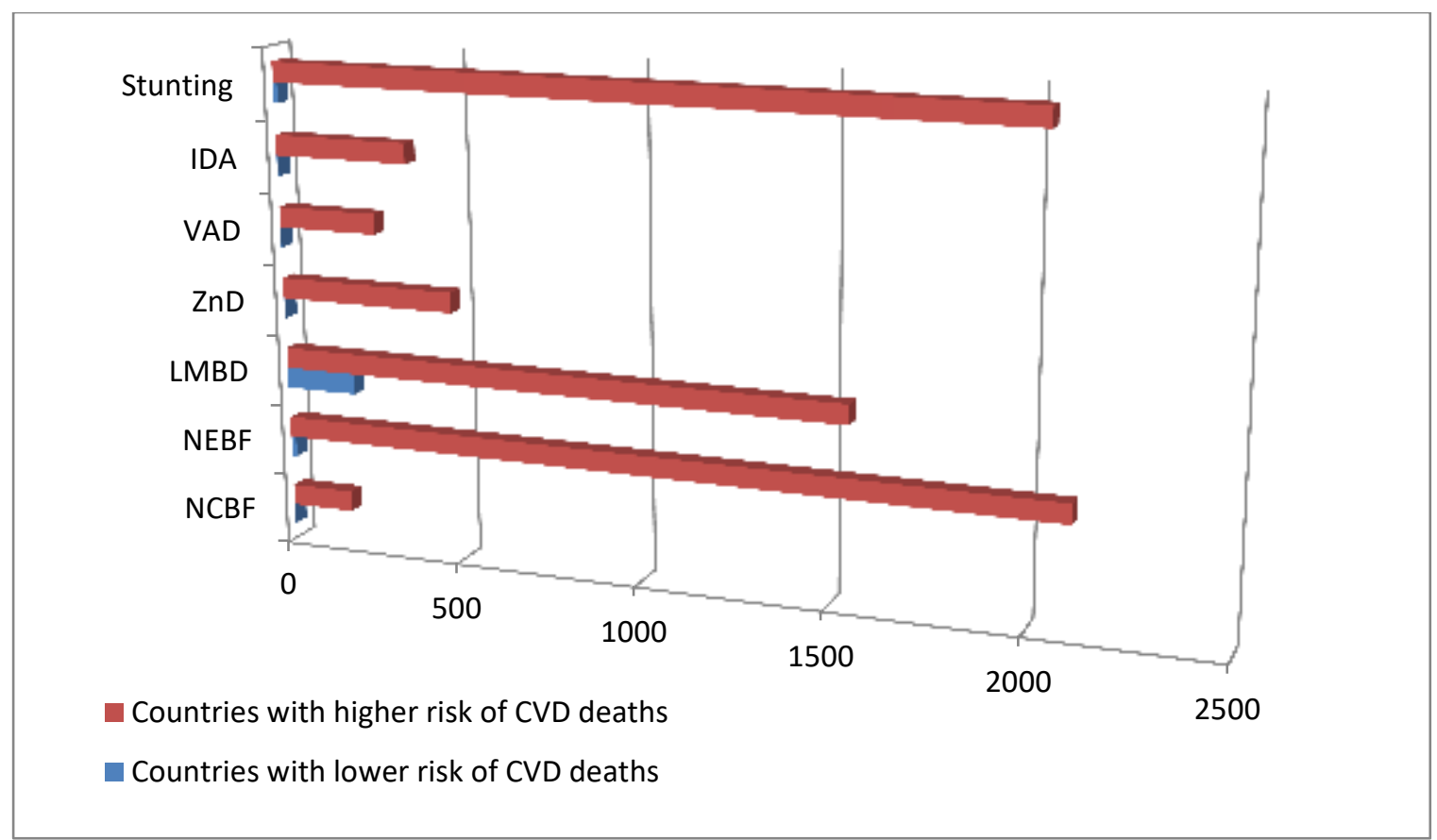

IDA: iron deficiency anemia, VAD: vitamin A deficiency, ZnD: zinc deficiency, LMBD: low bone mineral metabolism, NEBF: no exclusive breastfeeding, NCBF: no continued breastfeeding.

Figure (4) Comparing nutritional indices for stunting, micronutrient deficiencies and infant feeding practices as contributing to risk of death from cardiovascular disease in countries with higher burden vs. lower burden as per deaths due to high blood pressure and high cholesterol and high sugar blood levels.

Table (1) Comparing mean nutritional indices in countries with high risk and low risk of death from cardiovascular disease (CVD)

\begin{tabular}{|c|c|c|c|c|}
\hline $\begin{array}{l}\text { CVD Deaths } \\
\text { attributed to } \\
\text { nutritional or feeding } \\
\text { indices }\end{array}$ & $\begin{array}{c}\text { High risk countries } \\
\text { Range } \\
\text { Mean } \\
\pm \text { SD }\end{array}$ & $\begin{array}{c}\text { Low risk countries } \\
\text { Range } \\
\text { Mean } \\
\pm \text { SD }\end{array}$ & t-test & p-value \\
\hline Low Birth Weight & $\begin{array}{c}917-45207 \\
10650.44 \\
\pm 12758.56\end{array}$ & $\begin{array}{c}1-1202 \\
368.08 \\
\pm 350.39\end{array}$ & 2.647 & $0.029 *$ \\
\hline Wasting & $\begin{array}{c}81-8389 \\
2036 \\
\pm 2490.9\end{array}$ & $\begin{array}{c}4-501 \\
94 \\
\pm 136.97\end{array}$ & 2.34 & $0.047 *$ \\
\hline Stunting & $\begin{array}{c}2261-47255 \\
12353.44 \\
\pm 12830.98\end{array}$ & $\begin{array}{c}1-51 \\
11.69 \\
\pm 17.02\end{array}$ & 2.299 & $0.05^{*}$ \\
\hline Iron deficiency anemia & $\begin{array}{c}20-1982 \\
370.55 \\
\pm 582.8753\end{array}$ & $\begin{array}{c}1-25 \\
5 \\
\pm 6.11\end{array}$ & 1.783 & 0.112 \\
\hline Vitamin A deficiency & $\begin{array}{c}22-2064 \\
484.44 \\
\pm 621.58\end{array}$ & $\begin{array}{c}0.5-4 \\
1.19 \\
\pm 1.26\end{array}$ & 2.16 & $0.06^{*}$ \\
\hline $\begin{array}{l}\text { Low mineral bone } \\
\text { density }\end{array}$ & $\begin{array}{c}66-5197 \\
1553.667 \\
\pm 1543.81\end{array}$ & $\begin{array}{c}15-1013 \\
196.23 \\
\pm 256.87\end{array}$ & 2.75 & $0.025^{*}$ \\
\hline Zinc deficiency & $\begin{array}{c}0.5-1070 \\
274.11 \\
\pm 357.2\end{array}$ & $\begin{array}{c}0.5-18 \\
3.54 \\
\pm 4.86\end{array}$ & 2.191 & $0.06^{*}$ \\
\hline
\end{tabular}




\begin{tabular}{|l|c|c|l|l|}
\hline No Exclusive & $197-8719$ & $1-54$ & 2.4 & $0.043^{*}$ \\
breastfeeding & 2109.778 & 14.15 & & \\
& \pm 2462.85 & \pm 15.15 & & \\
\hline Discontinued & $8-919$ & $0.5-3$ & 1.81 & 0.108 \\
breastfeeding (no & 173.55 & 0.96 & & \\
continued BF) & \pm 269.33 & \pm 0.72 & & \\
\hline
\end{tabular}

*p-values statistically significant $<0.05$

Table (4) compares the weaning practices of foods introduced before six months of age. The HDL was significantly higher in both non-breastfed and breastfed children $(35.67 \pm 5.46 ; 32 \pm 4.98$ respectively) compared to those introduced foods after 6 months $(45.78 \pm 8.7 ; 47.18 \pm 10.85$ respectively) at $\mathrm{P}<0.001$ (HS). Only non-breastfed children had even higher LDL when introduced foods before and after 6 months $(95.67 \pm 7.23 ; 97 \pm 18.44)$ at $\mathrm{P}<0.001$. While, the LDL/HDL ratio was significantly higher in either group when foods were introduced at 4-6 months versus 6-9 months $(2.65 \pm 0.52 ; 3.08 \pm 0.68$; versus $2.1 \pm 0.28$; $2.12 \pm 0.46$ respectively) at $\mathrm{P}<0.007$ (HS).

The following results were obtained from the SSIDS in an urban setting in Cairo, Egypt:

There was a statistically significant difference between the two groups regarding HsCRP as it was significantly higher among the non-breastfed children compared to the breastfed ones $(\mathrm{m}=2.08 \pm 1.64$ vs. $\mathrm{m}=0.84 \pm 1.09$ respectively) . However there was no statistically significant difference regarding BMI, LDL, HDL and ratio of LDL /HDL (Table 2).

The mean SBP, DBP and HsCRP among mothers who had never breastfed their children were statistically significantly higher $(110 \pm 10.89 \mathrm{mmHg}, 71.43 \pm 6.51 \mathrm{mmHg}$ and $3.3 \pm 2.2 \mathrm{mg} / \mathrm{l}$ respectively). However there was no statistically significant difference regarding BMI, LDL, HDL and ratio of LDL /HDL between both groups (Table 3).

Table (2) Comparing biochemical risk factors (biomarkers) of cardiovascular disease in breastfed versus non-breastfed children

\begin{tabular}{|c|c|c|c|c|c|c|c|}
\hline \multirow{3}{*}{\multicolumn{2}{|c|}{ Variable }} & \multicolumn{4}{|c|}{ Type of feeding } & \multirow{3}{*}{$\mathbf{t}$} & \multirow{3}{*}{$\begin{array}{c}\text { p- } \\
\text { value }\end{array}$} \\
\hline & & \multicolumn{2}{|c|}{$\begin{array}{c}\text { Group I } \\
\begin{array}{c}\text { (Non-breastfed children) } \\
(\text { no. }=28)\end{array}\end{array}$} & \multicolumn{2}{|c|}{$\begin{array}{c}\text { Group II } \\
\begin{array}{c}\text { (Breastfed children) } \\
\text { (no.=32) }\end{array}\end{array}$} & & \\
\hline & & Mean \pm SD & Range & Mean \pm SD & Range & & \\
\hline \multirow[t]{2}{*}{ BMI } & $\left(\mathrm{kg} / \mathrm{m}^{2}\right)$ & $16.75 \pm 2.41$ & $\begin{array}{l}12.42- \\
19.37\end{array}$ & $15.71 \pm 1.92$ & $\begin{array}{l}12.8- \\
19.33\end{array}$ & 1.85 & $\begin{array}{l}0.07 * \\
(\mathrm{~S})\end{array}$ \\
\hline & Centile & $0 \pm 1.72$ & $-3-2$ & $-0.5 \pm 1.56$ & $-3-2$ & 1.18 & 0.24 \\
\hline \multicolumn{2}{|c|}{ Hs CRP(mg/l) } & $2.08 \pm 1.64$ & $0-4.3$ & $0.84 \pm 1.09$ & $0-3.9$ & 3.28 & $\begin{array}{l}0.002 * \\
(\mathrm{HS})\end{array}$ \\
\hline \multicolumn{2}{|c|}{ LDL(mg/dl) } & $94.93 \pm 11.77$ & $82-124$ & $95.94 \pm 15.6$ & $73-129$ & 0.28 & 0.78 \\
\hline \multicolumn{2}{|c|}{ HDL(mg/dl) } & $43.43 \pm 8.45$ & $29-61$ & $42.56 \pm 11.59$ & $27-64$ & 0.33 & 0.74 \\
\hline \multicolumn{2}{|c|}{ LDL/HDL } & $2.24 \pm 0.39$ & $\begin{array}{l}1.52- \\
3.17\end{array}$ & $2.38 \pm 0.63$ & $\begin{array}{l}1.41- \\
3.81\end{array}$ & 1.04 & 0.30 \\
\hline
\end{tabular}

BMI: body mass index , HsCRP: highly sensitive C-reactive protein ,

LDL: low density lipoprotein, HDL: high density lipoprotein, LDL/HDL: ratio of low density lipoprotein/high density lipoprotein, *p-value is significant (S), p-value is highly significant (HS).

Table (3) Comparing physical and biochemical risk factors of cardiovascular diseases in mothers who had never breastfed their children (group I) with mothers who had breastfed their children(group II):

\begin{tabular}{|c|c|c|c|c|c|c|}
\hline \multirow{3}{*}{ Variable } & \multicolumn{4}{|c|}{ Type of feeding } & \multirow{3}{*}{ t-test } & \multirow{3}{*}{ p-value } \\
\hline & \multicolumn{2}{|c|}{$\begin{array}{c}\text { Group I } \\
\text { (mothers who had never } \\
\text { breastfed their children) } \\
\text { (no.=28) }\end{array}$} & \multicolumn{2}{|c|}{$\begin{array}{c}\text { Group II } \\
\text { (mothers who had breastfed } \\
\text { their children) } \\
\text { (no.=32) }\end{array}$} & & \\
\hline & Mean \pm SD & Range & Mean \pm SD & Range & & \\
\hline BMI (kg/m2) & $26.84 \pm 2.71$ & $23.3-$ & $27.32 \pm 3.79$ & $22-33.9$ & 0.55 & 0.58 \\
\hline
\end{tabular}




\begin{tabular}{|c|c|c|c|c|c|c|}
\hline SBP (mm Hg) & $110 \pm 10.89$ & $90-120$ & $101.87 \pm 10.3$ & $90-120$ & 2.97 & $\begin{array}{c}0.004 * * \\
(\mathrm{HS})\end{array}$ \\
\hline $\begin{array}{c}\text { DBP (mm } \\
\text { Hg) }\end{array}$ & $71.43 \pm 6.51$ & $60-80$ & $66.56 \pm 6.4$ & $60-80$ & 2.91 & $\begin{array}{c}0.005^{* *} \\
(\mathrm{HS})\end{array}$ \\
\hline HsCRP (mg/l) & $3.3 \pm 2.2$ & $0-7.1$ & $1.72 \pm 1.96$ & $0-5.7$ & 2.93 & $\begin{array}{c}0.005 \\
(\mathrm{HS})\end{array}$ \\
\hline LDL(mg/dl) & $119.57 \pm 18.37$ & $92-150$ & $121.37 \pm 20.52$ & $80-148$ & 0.36 & 0.72 \\
\hline HDL(mg/dl) & $37.86 \pm 5.69$ & $29-46$ & $36.25 \pm 5.02$ & $31-45$ & 1.16 & 0.25 \\
\hline LDL/HDL & $3.22 \pm 0.68$ & $2.26-4.72$ & $3.37 \pm 0.55$ & $2.48-4.31$ & 0.93 & 0.35 \\
\hline
\end{tabular}

*BMI:body mass index *SBP: systolic blood pressure *DBP: diastolic blood pressure

*HsCRP: highly sensitive C-reactive protein *LDL: low density lipoprotein *HDL: high density lipoprotein

*LDL/HDL: ratio of low density lipoprotein/high density lipoprotein

**p-value is highly significant (HS)

Table (4) Comparing biochemical risk factors of cardiovascular disease in relation to timing of introduction of solids in breastfed and non-breastfed children

\begin{tabular}{|c|c|c|c|c|c|c|}
\hline \multicolumn{2}{|c|}{ Parameters under study } & \multicolumn{3}{|c|}{ Age of introduction of solids } & \multirow{2}{*}{ Test } & \multirow{2}{*}{ p-value } \\
\hline & & & r mean \pm & range & & \\
\hline \multirow{2}{*}{$\begin{array}{c}\text { LDL(mg/d) in } \\
\text { non-breastfed } \\
\text { children }\end{array}$} & At 4-6 months & 6 & $95.67 \pm 7.23$ & $87-103$ & \multirow{2}{*}{$\mathrm{F}=8.20$} & \multirow{2}{*}{$\begin{array}{l}0.001 \\
(\mathrm{HS})\end{array}$} \\
\hline & At 6-9 months & 22 & $97 \pm 18.44$ & $73-129$ & & \\
\hline \multirow{2}{*}{$\begin{array}{c}\text { LDL(mg/d) in } \\
\text { breastfed } \\
\text { children }\end{array}$} & At 4-6 months & 6 & $92.33 \pm 8.5$ & $83-102$ & \multirow[b]{2}{*}{$F=0.68$} & \multirow[b]{2}{*}{0.52} \\
\hline & At 6-9 months & 18 & $94.44 \pm 12.4$ & $82-124$ & & \\
\hline \multirow{2}{*}{$\begin{array}{c}\text { HDL(mg/d)in } \\
\text { non-breastfed } \\
\text { fed children }\end{array}$} & At 4-6 months & 6 & $35.67 \pm 5.46$ & $29-41$ & \multirow{2}{*}{$\mathrm{F}=3.98$} & \multirow{2}{*}{$\begin{array}{l}0.03 \\
(\mathrm{~S})\end{array}$} \\
\hline & At $6-9$ months & 18 & $45.78 \pm 8.7$ & $34-61$ & & \\
\hline \multirow{2}{*}{$\begin{array}{c}\text { HDL }(\mathrm{mg} / \mathrm{dl}) \text { in } \\
\text { breastfed } \\
\text { children }\end{array}$} & At 4-6 months & 6 & $32 \pm 4.98$ & $27-38$ & \multirow{2}{*}{$\mathrm{F}=8.20$} & \multirow{2}{*}{$\begin{array}{c}0.001 \\
(\mathrm{HS})\end{array}$} \\
\hline & At $6-9$ months & 22 & $47.18 \pm 10.85$ & $30-64$ & & \\
\hline \multirow{3}{*}{$\begin{array}{l}\text { LDL/HDL in } \\
\text { non-breastfed } \\
\text { children }\end{array}$} & At 4-6 months & 6 & $2.65 \pm 0.52$ & $2.02-3.17$ & \multirow{3}{*}{$F=6.09$} & \multirow{3}{*}{$\begin{array}{c}0.007 \\
(\mathrm{HS})\end{array}$} \\
\hline & $\begin{array}{c}\text { From 6-9 } \\
\text { months }\end{array}$ & 18 & $2.1 \pm 0.28$ & $1.52-2.53$ & & \\
\hline & After 9 months & 4 & $2.26 \pm 0.16$ & $2.12-2.4$ & & \\
\hline \multirow{2}{*}{$\begin{array}{c}\text { LDL/HDL in } \\
\text { breastfed } \\
\text { children }\end{array}$} & At 4-6 months & 6 & $3.08 \pm 0.68$ & $2.29-3.81$ & \multirow{2}{*}{$F=9.93$} & \multirow{2}{*}{$\begin{array}{c}<0.001 \\
(\mathrm{HS})\end{array}$} \\
\hline & At $6-9$ months & 22 & $2.12 \pm 0.46$ & $1.41-3$ & & \\
\hline \multirow{3}{*}{$\begin{array}{c}\text { HsCRP(mg/l) in } \\
\text { non-breastfed } \\
\text { children } \\
\end{array}$} & At $4-6$ months & 18 & $1.77 \pm 1.82$ & $0.4-4.1$ & \multirow{3}{*}{$\mathrm{F}=1.09$} & \multirow{3}{*}{0.35} \\
\hline & At 6-9 months & 4 & $2.33 \pm 1.58$ & $0-4.3$ & & \\
\hline & After 9 months & 6 & $0.7 \pm 0$ & $0.7-0.7$ & & \\
\hline \multirow{3}{*}{$\begin{array}{c}\text { HsCRP }(\mathrm{mg} / \mathrm{l}) \text { in } \\
\text { breastfed } \\
\text { children }\end{array}$} & At 4-6 months & 6 & $0.67 \pm 0.96$ & $0-0.6$ & \multirow{3}{*}{$\mathrm{F}=0.51$} & \multirow{3}{*}{0.61} \\
\hline & At 6-9 months & 22 & $1 \pm 1.22$ & 0-1.9 & & \\
\hline & After 9 months & 4 & $0.45 \pm 0.17$ & $0.3-3.9$ & & \\
\hline
\end{tabular}

\section{Discussion}

The number of deaths, as a proportion of global deaths from CVD, HBP and nutritional deficiencies, were lowest for the EMR as shown in figure (1). Still according to the global health observatory in 2015, EMR ranks second after Africa for the age-standardized noncommunicable disease (NCD) mortality, which is 11 percent higher than the global rate ${ }^{(2)}$. This is in line with global findings that CVD is the leading cause of NCD deaths in 2015 (17.7 million deaths, or 45\% of all NCD deaths) followed by cancers (8.8 million, or $22 \%$ of all NCD deaths), and respiratory diseases, including asthma, chronic obstructive pulmonary disease (3.9 million deaths) and diabetes mellitus (1.6 million deaths). This indicates that factors that increase risk of death from CVD can significantly increase the burden of death from NCD worldwide. Hence investing in such factors can have substantial savings for the world and allow for economic development.

EMR countries with highest burden of deaths from hypertension, as a risk factor for death from CVD, were Pakistan, Egypt, Iraq and Iran; representing almost two thirds of the region's burden of total deaths. They 
are also the countries with highest population in the region, which could be one way of explaining this finding. However the coincident increase in rates of obesity, HBS, high cholesterol levels, and pollution indicate that such countries are suffering from multiple risk factors for NCDs deaths, which can explain why the region is top on the list of NCD mortality globally ${ }^{(2)}$.

Globally deaths from nutritional deficiencies are lowest in the EMR countries compared to Americas and South East Asian regions. Again this could be attributed to the higher population numbers in these regions. However when we compared the mean deaths from nutritional deficiencies in the EMR countries, we found that countries with high risk of CVD also had the highest burden of deaths from nutritional deficiencies and poor feeding practices. Dietary factors were shown to contribute to deaths and disability adjusted life years (DALYs) from NCDs and in particular CVD. Diets low in fruits and vegetables, nuts and seeds, fish and omega-3 and high in sodium are the five top most important risk factors of NCDs. A study in Ethiopia showed that almost half of CVD deaths were caused by poor diet quality ${ }^{(12)}$.

Egypt was chosen to conduct an in-depth study, as a representative of the "high risk country group" in this study. The study showed that non breastfeeding mothers had HBP compared to breastfeeding mothers. Also, that the lipid prophiles in the non-breastfed children and their mothers, tend to increase risk of arteriosclerotic disease compared to the breastfed children and respective mothers. Given the very low rates of EBF in a country like Egypt (13.6\%) according to the latest demographic health survey in $2014^{(13)}$, this probably flags early infant feeding practices as early contributors to death from CVD, which could be reversed by optimal early infant feeding practices.

The effect of breastfeeding on CVD has been controversial. The Kramer study ${ }^{(9)}$ did not find any relationship between breastfeeding and cardiovascular health. On the other hand a prospective Study of 300 000 Chinese Women in 2017 in China ${ }^{(7)}$ compared the parous women who had never breastfed with ever breastfeeding and found a significantly lower risk of CVD, with 10\% lower risk of coronary heart disease and a $17 \%$ lower risk of stroke compared with women who had never breastfed. Each additional six months of breastfeeding per child was associated with a further decrease in risk of coronary heart disease and stroke. They concluded that a longer duration of breastfeeding was preventive against CVD ${ }^{(7)}$.

A meta-analysis for systolic blood pressure (SBP) which included 14 studies and 17 observations concluded that mean SBP was lower in breastfed infants compared to bottle-fed infants in most of the studies and observations ${ }^{(14)}$. Another study that pooled data from 10912 subjects in Brazil found that DBP was lower among participants who were breastfed than non-breastfed ${ }^{(15)}$. Moreover, a prospective cohort study in the United Kingdom studied SBP and DBP in 4763 children and found that blood pressure was consistently lower in the breastfed and decreased more with longer duration of breastfeeding ${ }^{(16)}$. This could be attributed to the taming effect of breastfeeding on the adrenocortical function, breastmilk content of endorphin and low salt content in breastmilk ${ }^{(17,18)}$. Also, there is emerging evidence of the role of microbiota in pathogenesis of hypertensive disease and atherosclerosis and that gut dysbiosis may predispose to CVD ${ }^{(19)}$. Exclusive breastfeeding has been shown to influence gut microbiota and reduce dysbiosis and thereby contribute to preventing $\mathrm{CVD}^{(20)}$.

For mothers, on the other hand, a prospective postpartum study for up to five months in 22 healthy women who were breastfeeding vs. 23 formula feeding mothers reported that women who practiced breastfeeding had lower DBP compared to those who did not breastfeed ${ }^{(21)}$. Other workers supported such findings of lower blood pressure among women who breastfed their children ${ }^{(22,23)}$. The underlying factors that may explain such findings may be related to programming the child to reduced cortisol levels in response to stress. One study showed the coincident reduced cortisol in both mothers and babies in the breastfed, but not in the non-breastfed ${ }^{(17)}$. Another study showed how early continuous skin-to-skin care between mother and baby can reduce cortisol levels in the mother-infant dyad ${ }^{(18)}$.

Another important biomarker of CVD is HsCRP ${ }^{(23)}$ whose levels were reported to be high in non-breastfed children and mothers in our SSCIS. Other investigators reported that HsCRP was a fifth lower in breastfed for at least three months and by 26.7 per cent, when breastfed for six to 12 months and by 29.6 per cent when breastfed over 12 months ${ }^{(24)}$. 
Duration of breastfeeding is protective against CVD. A study in the United States among 139,681 postmenopausal women showed that longer duration of breastfeeding reduced risk of CVD, hypertension, self-reported diabetes, hyperlipidemia. They reported a dose-response relationship among women who reported a lifetime history of more than 12 months of lactation with less likelihood to develop hypertension, diabetes, hyperlipidemia or CVD ${ }^{(3)}$. Other workers have confirmed such findings ${ }^{(22,25,26)}$.

Our study showed that indices of nutritional status, that include low birth weight, stunting and wasting, were associated with increased deaths from CVD. Other workers have shown that suboptimal dietary factors, particularly low intakes of fruits and vegetables, can influence DALYs and deaths from CVD ${ }^{(12,27)}$. A study in Egypt showed that micronutrient deficiency states co-exist with obesity and that serum Zinc and iron correlated with HDL and negatively with leptin and cholesterol ${ }^{(28)}$. Other studies have shown significant gaps in the diet of populations living in the EMR ${ }^{(29,30)}$. Vitamin D intake was found to improve cases with heart failure ${ }^{(31)}$ and have been shown to have cardiopotent metabolic effects on HBP ${ }^{(32)}$. While vitamin $\mathrm{A}$ is an important biomarker of $\mathrm{CVD}^{(33)}$ and can prevent $\mathrm{CVD}^{(33)}$. Serum retinol and breastmilk retinol were found to work in synergy with iron and zinc to enhance their metabolic effects ${ }^{(34)}$. Although breastfed infants have been shown to have low iron and vitamin D especially in developing countries with poorly nourished multiparous mothers ${ }^{(35,36)}$ breastfeeding remains an important source of vitamins, minerals and trace, particularly in the EMR ${ }^{(37)}$.

In this study we showed that early introduction of weaning foods before 6 months was associated with increased biomarkers linked with CVD. Many misbeliefs and misconceptions are associated with poor feeding practices and earlier introduction of weaning foods particularly substitution of breastfeeding with foods and thereby reducing frequency of breastfeeding in the second year ${ }^{(38)}$, which can shorten the duration of breastfeeding. Foods for infants that are high in protein, salt and low in vegetables and fruits are linked with high rates of obesity that predispose to $\operatorname{CVD}$ and $\operatorname{HBP}^{(39,40)}$. Early introduction of foods augment health related consequences in later life ${ }^{(41)}$. The most recent World Health Assembly resolution ${ }^{(42)}$ of marketing of infant foods beyond six months recognizes the importance of controlling marketing practices that push mothers to introduce these foods early to breastfed babies ${ }^{(42)}$.

In conclusion our findings build on a growing body of evidence that supports the beneficial effects of early exclusive and prolonged breastfeeding on blood pressure and cardiovascular health. It supports other studies that show that the UNICEF and WHO recommendation for EBF and for prolonging the duration of breastfeeding to two years, or more, benefits both maternal and child health. Improving breastfeeding rates in these countries can be pivotal in reducing global deaths from CVD, obesity and hypertension, and in particular, protecting mothers and children from the long term morbidity associated with nutritional deficiencies, obesity, HBS, HBP and other risk factors of CVD.

\section{References}

[1] Ritchie H and Roser M. Our World in Data, Causes of death, published February, 2018 https://ourworldindata.org/causes-of-death. 2018.

[2] World health Organization. Global status report on non-communicable diseases. WHO, Geneva, Switzerland, 2014.

[3] Schwarz E.B., Ray R.M., Stuebe A.M, Allison M.A., Ness R.B., Freiberg M.S., Cauley J.K. Duration of lactation and risk factors for maternal cardiovascular disease. Obstet Gynecol. 2009; 113(5): 974-982. doi:10.1097/01.AOG.0000346884.67796.ca.

[4] Stuebe AM. Michels KB. Willett WC. Manson JE. Rexrode K. Rich-Edwards JW. Duration of lactation and incidence of myocardial infarction in middle to late adulthood. Am $\mathrm{J}$ Obstet Gynecol. 2009;200:138.e1-8.

[5] Lee SY. Kim MT. Jee SH. Yang HP. Does long-term lactation protect premenopausal women against hypertension risk? A Korean women's cohort study. Prev Med. 2005;41:433-438.

[6] Horta BL, Bahl R, Martinés JC, Victora CG; World Health Organization Evidence on the long-term effects of breastfeeding: systematic reviews and meta-analysis . Geneva: WHO; 2007.

[7] Peters, SAE; Yang L, Guo Y, Chen Y, Bian Z, Du J, Yang J., Li S, Li L., Woodward M., Chen Z.; on behalf of the China Kadoorie Biobank Collaboration Group. Breastfeeding and the risk of maternal cardiovascular disease: A Prospective Study of 300000 Chinese Women. J Am Heart Assoc. 2017;6:e006081. 
[8] Ramirez-Silva I, Rivera JA, Trejo-Valdivia B, Martorell R., Stein AD., Romieu I, Barraza-Villarreal A, Ramakrishnan U. Breastfeeding status at age 3 months is associated with adiposity and cardiometabolic markers at age 4 years in Mexican children. The Journal of Nutrition 2015; 145 (6): 1295-1302.

[9] Kramer MS, Matush L, Vanilovich I, Platt RW, Bogdanovich N, Sevkovskaya Z, Dzikovich I, Shishko G, Collet JP, Martin RM, et al.; PROBIT Study Group Effects of prolonged and exclusive breastfeeding on child height, weight, adiposity, and blood pressure at age 6.5 years: Evidence from a large randomized trial. Am. J. Clin. Nutr 2007;86:1717-21.

[10] World Health Organization data base for Global Health estimates 2015: estimated deaths by age, sex and cause. WHO, Geneva, Switzerland.

[11] Attia MAM. Influence of early feeding practices on biomarkers of cardiovascular diseases in later life. Thesis submitted for fulfillment of master degree In Pediatrics. Supervised by Azza Abul-Fadl, Osama Sanad, Amal Abouel-Fadle, Ola G. ElBeheiry. Pediatric department, Faculty of medicine, Benha University, Egypt.

[12] Melaku, Y. A., Temesgen, A. M., Deribew, A., Tessema, G. A., Deribe, K., Sahle, B. W., Abera, S. F., Bekele, T., Lemma, F., Amare, A. T., Seid, O et al. The impact of dietary risk factors on the burden of non-communicable diseases in Ethiopia: findings from the Global Burden of Disease study 2013. The international journal of behavioral nutrition and physical activity. 2016;13(1), 122. doi:10.1186/s12966-016-0447-X

[13] DHS, 2014

[14] Martin RM, Gunnell D, Smith GD. Breastfeeding in infancy and blood pressure in later life: systematic review and meta-analysis. Am J Epidemiol. 2005, 1;161(1):15-26.

[15] Fall CH, Borja JB, Osmond C, Richter L, Bhargava SK, Martorell R, et al. Infant-feeding patterns and cardiovascular risk factors in young adulthood: data from five cohorts in low-and middle-income countries. Int J Epidemiol. 2011;40(1):47-62.

[16] Martin RM., Ness AR., Gunnel D., Emmett P., Smith GD for the ALSPAC study team. Does BreastFeeding in Infancy Lower Blood Pressure in Childhood? The Avon Longitudinal Study of Parents and Children (ALSPAC). Circulation. 2004;109:1259-1266.

[17] Stenius F., Theorell T., Lilja G, Scheynius A, Alm J, Lindblad F. Comparisons between salivary cortisol levels in six-months olds and their parents. Psychoneuroendocrinology. 2008; 33(3):352-9.

[18] Morelius E, Ortenstrand A., Theodorsson E., Frostell A. A randomized trial of continuous skin-toskin contact after preterm birth and the effect on salivary cortisol, parental stress, depression and breastfeeding. Early Human Development. 2015; 91(1):63-70.

[19] $\mathrm{Ma} \mathbf{J}$ and Houka L. The role of microbiota in atherosclerosis and hypertension. Frontiers in Pharmacology. 2018 9:1082.

[20] Ho NT, Li F, Lee-Saewar KA, Tun HM, Brown BP, Pannaraj PS., et al. Meta-analysis of effects of exclusive breastfeeding on infant gut microbiota across populations. Nature communication. 2018; 9:4169.

[21] Stuebe AM. Michels KB. Willett WC. Manson JE. Rexrode K. Rich-Edwards JW. Duration of lactation and incidence of myocardial infarction in middle to late adulthood. Am $\mathrm{J}$ Obstet Gynecol. 2009;200:138.e1-8.

[22] Groer MW, Jevitt CM, Sahebzamani F, Beckstead JW, Keefe DL. Breastfeeding status and maternal cardiovascular variables across the postpartum. J Womens Health (Larchmt). 2013;22(5):453-9.

[23] Ridker PM. Clinical application of C-reactive protein for cardiovascular disease detection and prevention. Circulation 2003; $107: 363-9$.

[24] Williams MJ, Williams SM and Poulton $\mathrm{R}$ : Breast feeding is related to $\mathrm{C}$ reactive protein concentration in adult women. J Epidemiol Community Health,2006; 60 (2): 146-8.

[25] Ebina S. Kashiwakura I. Influence of breastfeeding on maternal blood pressure at one month postpartum. Int J Womens Health. 2012;4:333-339.

[26] Jonas W, Nissen E, Ransjö-Arvidson AB, Wiklund I, Henriksson P, Uvnäs-Moberg. Short- and longterm decrease of blood pressure in women during breastfeeding. Breastfeed Med. 2008 Jun;3(2):1039.

[27] Leenders M, Sluijs I, Ros MM, Boshuizen HC, Siersema PD, Ferrari P, Weikert C, Tjønneland A, Olsen A, Boutron-Ruault M-C. Fruit and vegetable consumption and mortality: European 
prospective investigation into cancer and nutrition. Am J Epidemiol. 2013;15:178(4):590-602. [PubMed].

[28] Azab SF, Saleh SH, Elsaeed WF, Elshafie MA, Sherief LM, Esh AM. Serum trace elements in obese Egyptian children: a case-control study. Ital J Pediatr. 2014;40:20. Published 2014 Feb 20. doi:10.1186/1824-7288-40-20.

[29] Naja F, Shatila H, Meho L, Alameddine M, Haber S, Nasreddine L, Sibai AM, Hwalla N.Gaps and opportunities for nutrition research in relation to non-communicable diseases in Arab countries: Call for an informed research agenda. Nutr Res. 2017 Nov;47:1-12. doi: 10.1016/j.nutres.2017.07

[30] Musaiger AO, Hassan AS, Obeid O. The paradox of nutrition-related diseases in the Arab countries: the need for action. Int J Environ Res Public Health. 2011;8(9):3637-71.

[31] Rai V, Agrawal DK. Role of Vitamin D in Cardiovascular Diseases. Endocrinol Metab Clin North Am. 2017;46(4):1039-1059.

[32] Chen S, Sun Y, Agrawal DK. Vitamin D deficiency and essential hypertension. J Am Soc Hypertens. 2015; 9(11):885-901. [PubMed: 26419755]

[33] Lima IOL, Peres WAF, Cruz S, Ramalho A. Association of Ischemic Cardiovascular Disease with Inadequacy of Liver Store of Retinol in Elderly Individuals. Oxid Med Cell Longev. 2018;2018:9785231. Published 2018 Apr 2. doi:10.1155/2018/9785231

[34] Tanumihardjo SA, Russell RM, Stephensen CB, et al. Biomarkers of Nutrition for Development (BOND)-Vitamin A Review. J Nutr. 2016;146(9):1816S-48S.

[35] Ziegler E.E., Nelson S.E., Jeter J.M. Iron Stores of Breastfed Infants during the First Year of Life. Nutrients. 2014;6:2023-2034. doi: 10.3390/nu6052023. [PMC free article] [PubMed] [CrossRef]

[36] Henderson A. Vitamin D and the breastfed infant. J. Obstet. Gynecol. Neonatal Nurs. 2005;34:367372. doi: 10.1177/0884217505276157. [PubMed] [CrossRef]

[37] Hwalla N, Al Dhaheri AS, Radwan H, et al. The prevalence of micronutrient deficiencies and inadequacies in the middle east and approaches to interventions. Nutrients. 2017;9(3):229. Published 2017 Mar 3. doi:10.3390/nu9030229.

[38] Jonsdottir O.H., Thorsdottir I., Hibberd P.L., Fewtrell M.S., Wells J.C., Palsson G.I. et al. (2012) Timing of the introduction of complementary foods in infancy: a randomized controlled trial. Pediatrics 130, 1038-1045.

[39] Escribano J., Luque V., Ferre N., Mendez-Riera G., Koletzko B., Grote V. et al. (2012) Effect of protein intake and weight gain velocity on body fat mass at 6 months of age: the EU Childhood Obesity Programme. International Journal of Obesity (2005) 36, 548-553.

[40] Weber M., Grote V., Closa-Monasterolo R., Escribano J., Langhendries J.P., Dain E. et al. (2014) Lower protein content in infant formula reduces BMI and obesity risk at school age: follow-up of a randomized trial.

[41] Hörnell A, Lagström H, Lande B, Thorsdottir I. Breastfeeding, introduction of other foods and effects on health: a systematic literature review for the 5 th Nordic Nutrition Recommendations.Food Nutr Res. 2013 Apr 12;57. doi: 10.3402/fnr.v57i0.20823. Print 2013.

[42] Resolution WHA65.6. Maternal, infant and young child nutrition. In: Sixty-fifth World Health Assembly, Geneva, 21-26 May 2012. Geneva: World Health Organization; 2012

[43] Ram KT, Bobby P, Hailpern SM, Lo JC, Schocken M, Skurnick J, et al. Duration of lactation is associated with lower prevalence of the metabolic syndrome in midlife-SWAN, the study of women's health across the nation. Am J Obstet Gynecol. 2008;198:268.e1-268.e6.

[44] Kelishadi R, Farajian S. The protective effects of breastfeeding on chronic non-communicable diseases in adulthood: A review of evidence. Adv Biomed Res. 2014 Jan 9;3:3. doi: 10.4103/22779175.124629. eCollection 2014.

[45] UNICEF-WHO-The World Bank. Joint child malnutrition estimates (http://apps.who.int/gho/data/). 